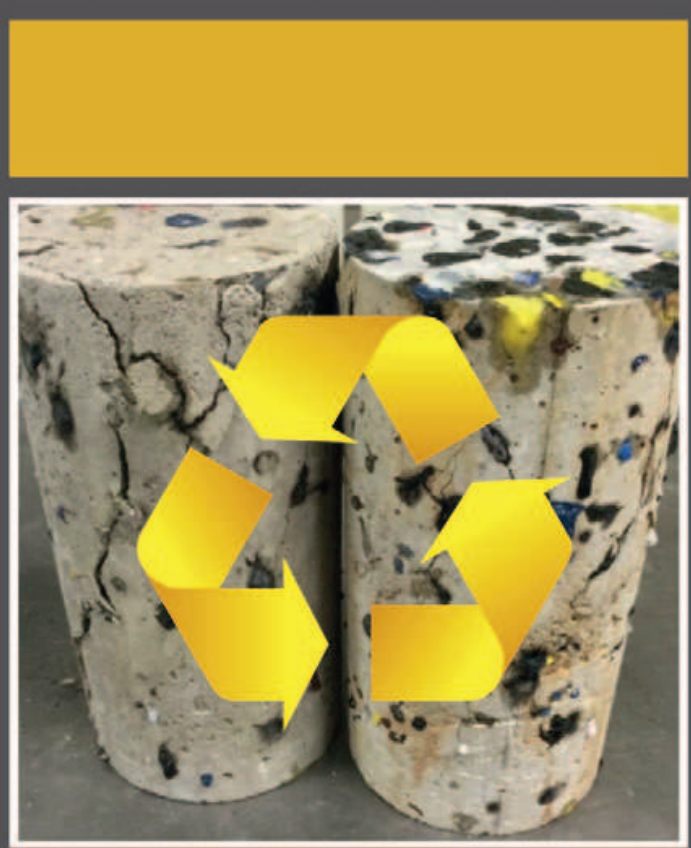

Use of Recycled

Plastics in

Eco-efficient

concrete

Edited by Fernando Pacheco-Torgal, Jamal Khatib, Francesco Colangelo, Rabin Tuladhar 


\title{
Introduction to the use of recycled plastics in eco-efficient concrete
}

\author{
F. Pacheco-Torgal \\ C-TAC Research Centre, University of Minho, Guimarães, Portugal
}

\subsection{The waste plastic problem}

Deriving from the Greek word "plastikos" meaning fit for moulding, plastics comprise mainly two broad categories (thermoplastics and thermosetting plastics). The former include plastics (polyethylene, polypropylene, polysterene, polycarbonates, etc.) that can be heated up to form products and if needed can be reheated and melted again for new forms. In contrast, the latter (polyurethane, polyesters, phenolic and acrylic resins, silicone, etc.) can be melted and formed, but unlike thermoplastics cannot be remelted. The global production of fossil-based plastics has grown more than 20-fold since 1964 to 322 million ton in 2015 (Wei and Zimmermann, 2017; PlasticsEurope, 2017). Not only the production of plastics consumes yearly $4 \%-8 \%$ of the global crude oil extraction meaning that if plastics are disposed instead of being recycled, these resources are lost but the worst part is that plastic waste is harmful because pigment contains many trace elements that are highly toxic and need hundreds of years to degrade (Huysman et al., 2017). More worrying is the several millions of tons of plastic waste that are entering the ocean each year, for quite some time, whose damaging action has been addressed by several authors (Eriksen et al., 2014; Jambeck et al., 2015; Sussarellu et al., 2016; Green et al., 2016; MacArthur, 2017; Lamb et al., 2018). Between 8 and 24 tons of plastic waste enter oceans each minute (Haward, 2018).

According to ten Brink et al. (2018), the annual cost of marine litter is conservatively estimated at US\$ 40 billion. And in July 19, 2017 Science magazine published an article warning that by 2050 , we'll have produced 26 billion tons of plastic waste, half of which will be dumped in landfills and the environment (Guglielmi, 2017). It's then no surprise that target 14.1 of the 2030 Agenda for Sustainable Development seeks to prevent and significantly reduce marine pollution of all kinds, in particular, from land-based activities, including marine debris, by 2025. Yes, it's true that on 17th of April 2018 a paper published in the Proceeding of the National Academy of Sciences of the United States of America (Austin et al., 2018) reported the discovery of an enzyme that can digest highly crystalline PET and also polyethylene-2,5furandicarboxylate (PEF). However, as Oliver Jones, analytical chemist at RMIT University in Melbourne, recognized "there is still a way to go before you could recycle large amount of plastic with enzymes" (Gabbatiss, 2018). But a more wise 
position was made by Adisa Azapagic, at the University of Manchester who mentioned that "A full life-cycle assessment would be needed to ensure the technology does not solve one environmental problem-waste-at the expense of others, including additional greenhouse gas emissions" (Carrington, 2018). And if a lesson can be extracted from this case, it is that scientists should have some lessons on public communication, a problem recognized several years ago (Soapbox Science, 2012; Goldstein, 2012; Grant, 2016). In the meantime a study published on May of 2018 showed that each liter of sea ice on the Arctic contained around 12,000 particles of plastic (La Daana et al., 2018). No wonder then that a previous study (Wilcox et al., 2015) revealed that around $90 \%$ of seabirds have plastic waste particles in their gut that they mistakenly took to be fish eggs. Also, Rochman (2018) recently showed that the ocean is not the only place to suffer damaging environmental impacts. Around 26 million tons of plastic waste are generated in Europe every year, which makes Europe the second largest producer of plastic materials, being responsible for $20 \%$ of the world production. Packaging applications, the largest application sector, represent 39.6\% of the total plastic demand (Huysman et al., 2017). In the past years significant share of European waste plastics leave the EU to be treated in third world countries, where different environmental standards may apply (EUROSTAT, EuropePlastics). However, since January of 2018 China decided to ban the imports of 24 kinds of waste including waste plastic which will aggravate the problem of plastic waste in Europe. And that is why plastic waste is one of the five priority areas in the EU action plan for the circular economy-CE (EC, 2015a). The CE concept may have been inspired by Rachel Carson's Silent Spring and the "limits to growth" thesis of the Club of Rome in the 1970s (Winans et al., 2017) and is being promoted by the EU, but several national governments still argue (Geissdoerfer et al., 2017) that the conceptual relationship between the CE and sustainability is not clear, having detrimental implications for the advancement of sustainability science. Others (Korhonen et al., 2018) mentioned that the CE practice has almost exclusively been developed and led by practitioners, that is, policy-makers, businesses, business consultants, business associations, and business foundations and as a result the research content of the CE concept is superficial and unorganized.

Still in the European Union context, looking into the past is worth remembering that the previous Directive 94/62/EC had imposed a recycling target which required 22.5\% of waste plastic packaging to be recycled. This target increased toward 55\% by 2030 (EC, 2015b) but on March 14 of the 2017 the European Parliament voted for legislation to aim for a recycling rate target of $70 \%$ by 2030 , with a proposed $80 \%$ target for packaging materials-including paper, cardboard, plastics, glass, metal, and wood. This constitutes a high ambition postured by the EU and there is still some controversy regarding job creation in the field of waste recycling. While the report cited by the European Parliament mentioned the possibility of creation of $1-3$ million jobs (IP, 2017) the fact is that the European Commission has presented a much lower number of just 170,000 direct jobs (Politico, 2018). Most of these optimistic projections usually tend to forget that as Cooper and Gutowski (2017) recently pointed the fact that reusing a product does not guarantee an environmental benefit because of the need to upgrade old product efficiencies and the fact that more efficient new products can be on the 
market. For instance, as contradicting as it may seem, Dunant et al. (2018) showed that reused steel is somewhat more expensive than new steel elements. Fig 1.1 shows plastic post-consumer waste rates of recycling, energy recovery, and landfill per country in 2016 and also the group of 10 countries that have implemented landfill restrictions. The figure illustrates in a very clear way the effort that needs to be taken to close the gap between the state-of-the-art plastic waste recycling and the new recycling targets. Of course energy recovery is nothing more than incineration (Eriksson and Finnveden, 2017).

Also the proof that the new and ambitious waste plastic recycling approved by the European Parliament could be hard to achieve is given by Karl-H. Foerster, executive director of industry organization Plastics Europe, who responded to the parliamentary proposals, saying that: "Taking into account today's recycling technology, we already
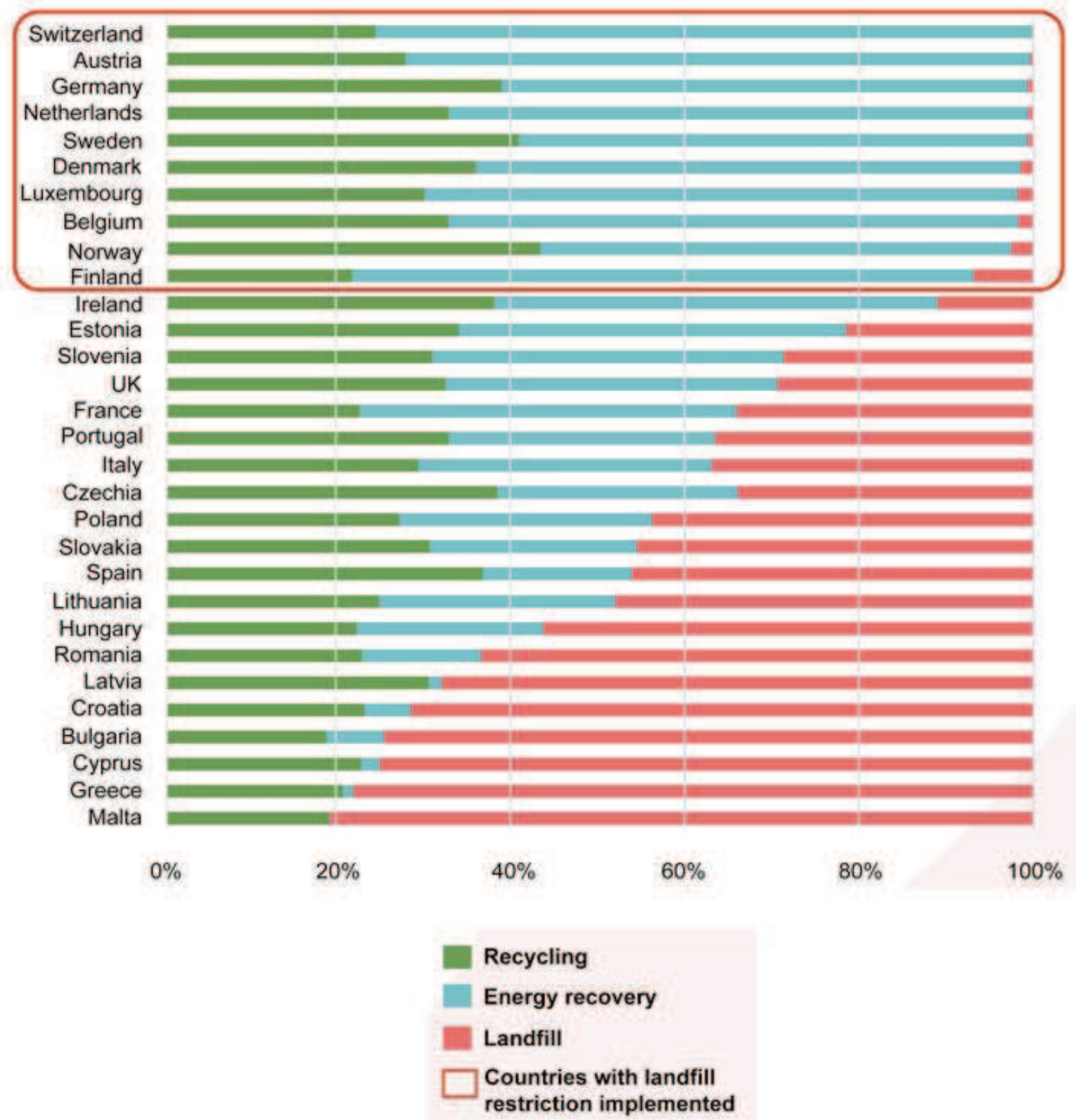

Figure 1.1 Plastic waste rates of recycling, energy recovery, and landfill per country (Plastics, 2017). 
consider that the 55\% plastics packaging preparing for re-use and recycling target proposed by the Commission is challenging. We would therefore like to call on the Presidency of the Council to carefully assess the impact prior to adopting any substantive amendment to the rules on the calculation initially proposed by the Commission." That position however must be seen in the light of the interests of the associates of Plastics Europe which are in the business of plastic manufacture and not in the business of waste plastic recycling. Of course, some European countries like the Netherlands, which in 2014 already recycled 50\% of (packaging) plastics, aiming for 52\% in 2022 (Gradus et al., 2017) will be in a better position to achieve this requirements. Be there as it may, the truth is that even countries with top performance concerning plastic waste recycling like Austria recognized that in order to achieve the proposed increased target major steps will be needed with respect to both collection and sorting of waste plastic (Van Eygen et al., 2018). This also means that even in Europe there's still much to do in order to aim at a 100\% recycling target (zero plastic waste scenario). In January 16 of 2018 the European Strategy for Plastics in a Circular Economy was released (COM, 2018). The document confirmed that more than $85 \%$ of plastic was sent to China. The document mentions that internalizing the environmental costs of landfilling and incineration through high or gradually rising fees or taxes could improve the economics of plastic recycling. However, this is just wishful thinking lacking a sound study. More likely it could constitute an incentive for illegal dumping or for exportation of plastic wastes to Africa as was mentioned in a United Nations University study (PiP, 2017) meaning that at this moment it is not possible to forecast how increasing recycling targets and the use of internalizing the environmental costs through rising fees or taxes may lead to an increase of smuggling waste to third world countries. The concept of eco-efficiency was firstly coined in the book Changing Course (Schmidheiny, 1992) in the context of 1992 Earth Summit process. This concept includes "the development of products and services at competitive prices that meet the needs of humankind with quality of life, while progressively reducing their environmental impact and consumption of raw materials throughout their life cycle, to a level compatible with the capacity of the planet." All of these give an important value to the option of recycling waste plastics through concrete, which is the most consumed material in our planet, about 25 gigatonnes per year around 3.5 ton per capita (Hossain et al., 2018). Not to mention the several billion tons of asphalt concrete used by the pavement industry each year. The use of recycled plastics in eco-efficient concrete can be done mainly by replacing natural aggregates, as binders and also as recycled fibers, allowing for improvements in the ductility of concrete composites. Those are the areas covered by this book.

\subsection{Outline of the book}

This book thus provides an updated state-of-the-art review on the use of recycled plastics in eco-efficient concrete.

Part I encompasses processing of plastic wastes (Chapters 2-4). 
Chapter 2 concerns techniques for the separation of plastic waste namely gravity separation, electrostatic separation, magnetic density separation, flotation, and sensor-based sorting. Auxiliary technologies usually found in plastic recycling plants are also described: magnetic and Eddy current separators. The importance of recycled plastic quality control and product certification is strongly pointed out, reporting both traditional and advanced quality measurement techniques.

Chapter 3 discusses hydraulic separation of plastic waste. This chapter presents an original device for the hydraulic separation of plastic polymers from mixtures. An extensive experimental campaign was conducted to investigate the effectiveness of the apparatus, using two geometric arrangements, nine hydraulic configurations, and three selections of polymers at three stages of a material's life cycle. Experimental data were also employed to validate a numerical model developed within the framework of Computation Fluid Dynamics. The separation results were evaluated in terms of grade and recovery of a useful material.

Chapter 4 presents the case for the production of recycled plastic fibers. The production process includes melt-spinning and hot-drawing processes, which increase crystallinity of the plastic polymer fibers and improve its mechanical properties.

Part II concerns the case of concrete with recycled plastic as aggregate or binder (Chapters 5-15).

Chapter 5 reviews the fresh properties of concrete with plastic aggregates. The chapter also reviews the case for fresh properties of self-compacting concrete.

Chapter 6 covers mostly the mechanical strength of concrete with polyvinyl chloride (PVC) aggregates including compressive and tensile strength and modulus of elasticity.

Chapter 7 provides a comprehensive review of concrete containing Expanded Polystyrene (EPS), covers recent research, including some recent research by the authors, with some details on the compositions of concrete mixes, presentation, and discussion of the results obtained. The review includes the influence of different amounts of EPS as a replacement for natural aggregates on the different mechanical, physical, and durability properties of lightweight aggregate concretes (LWAC). The chapter also includes the methods and techniques for recycling waste EPS to be utilized in concrete.

Chapter 8 deals with the use of polyolefin waste aggregates (PWA) obtained from recycled plastics and used as plastic aggregates to replace the natural ones to produce lightweight aggregate concrete (LWAC). The mechanical properties (compressive and tensile strength) and physical properties (porosity, density, and thermal stability) are determined. Furthermore, the postfire residual mechanical performance, ultrasonic testing, and compression force are evaluated.

Chapter 9 is concerned with waste polypropylene-based aggregates, in terms of its physical, mechanical, and hygric properties and, in particular, of thermal attributes and optimum energy performance in building construction.

Chapter 10 addresses polymers for enhancing neutron radiation shielding of concrete. Past research in the field is reviewed. The feasibility issues and concerns while using virgin and waste pulverized High-density polyethylene (HDPE) polymeric materials as partial replacement to fine aggregates for making concrete mixes with enhanced neutron radiation shielding characteristics are discussed. The fresh and 
hardened properties of these mixes and their effect on neutron radiation shielding are also discussed.

Chapter 11 reviews the reuse of dioctyl terephthalate (DOTP) obtained from waste PET into concrete. Fresh properties as well as mechanical properties of hardened concrete are reviewed, along with thermal conductivity. Performance comparisons between DOTP concrete and PET concrete are also reviewed.

Chapter 12 covers studies investigated in the usage of PET wastes in asphalt mixture. The volume and mechanical properties of asphalt mixtures containing PET wastes along with the physical characteristic of the PET-modified binder are examined.

Chapter 13 discloses results on a case study of asphalt concrete performance with different plastic wastes. Mechanical properties and durability parameters are covered. Emissions footprint is also covered.

Chapter 14 discusses the need of stabilization of asphalt concrete and different stabilizer materials using recycling plastics. Suitable methods for incorporating waste plastics, advantages of each, performance of waste plastic added mixtures are discussed in detail with brief information on some field evaluations.

Chapter 15 reviews the use of recycled plastic as partial replacement of bitumen in asphalt concrete. The need for stabilization of asphalt concrete is reviewed. The performance of asphalt concrete with plastics is also addressed.

Finally, Part III covers concrete with recycled plastic fibers (Chapters 16-22).

Chapter 16 surveys the usage of metalized plastic waste (MPW) as a cement concrete constituent in a macrofibrous form. The chapter focuses on how to obtain the optimum quantity of MPW fibers with a suitable size to be used in concrete and changes in the deformation response due to the axial compression along with the evaluation of preliminary material properties.

Chapter 17 addresses concrete with PVC fibers in the fresh and hardened state. It is suggested that the use of PVC fibers, either $0.8 \%$ (by weight of cement) or $0.2 \%$ (by volume of concrete), could significantly improve the performances of concrete. Limitations and practical issues on the utilization of PVC fibers in concrete mixes are identified. Hence, recommendations and future research needs on the practical implications of the use of PVC fibers are given at the end of the chapter.

Chapter 18 addresses the case of polymers added to concrete in the form of binder or as discrete elements (fibers) or continuous (strips) can limit the presence of cracks and especially avoid the corrosion processes in reinforced concrete structural elements. In more detail, the effect of polyethylene terephthalate (PET) on concrete mix is especially considered. Laboratory results of concrete reinforced with PET fibers derived from recycled water bottles and with different shapes are analyzed.

Chapter 19 presents an overview of physical and mechanical properties of concrete containing recycled carpet waste fibers, as well as the carpet structure and fiber properties.

Chapter 20 gives details of a case study on the performance of asphalt concrete reinforced with recycled PET fibers.

Chapter 21 closes Part III with a chapter on the life cycle assessment. The production of $100 \%$ recycled polypropylene fibers is compared with the environmental impacts of virgin PP fibers and steel reinforcing mesh. 


\section{References}

Austin, H.P., Allen, M.D., Donohoe, B.S., Rorrer, N.A., Kearns, F.L., Silveira, R.L., et al., 2018. Characterization and engineering of a plastic-degrading aromatic polyesterase. Proceedings of the National Academy of Sciences 201718804.

Carrington, D., 2018. Scientists Accidentally Create Mutant Enzyme that Eats Plastic Bottles. https://www.theguardian.com/environment/2018/apr/16/scientists-accidentally-createmutant-enzyme-that-eats-plastic-bottles.

COM, 2018. 28 Final. A European Strategy for Plastics in a Circular Economy. Brussels, 16.1.2018. http://ec.europa.eu/environment/circular-economy/pdf/plastics-strategy.pdf.

Cooper, D.R., Gutowski, T.G., 2017. The environmental impacts of reuse: a review. Journal of Industrial Ecology 21 (1), 38-56.

La Daana, K.K., Gårdfeldt, K., Lyashevska, O., Hassellöv, M., Thompson, R.C., O’Connor, I., 2018. Microplastics in sub-surface waters of the Arctic Central Basin. Marine Pollution Bulletin 130, 8-18.

Dunant, C.F., Drewniok, M.P., Sansom, M., Corbey, S., Cullen, J.M., Allwood, J.M., 2018. Options to make steel reuse profitable: an analysis of cost and risk distribution across the UK construction value chain. Journal of Cleaner Production 183, 102-111.

EC, 2015a. Closing the Loop - an EU Action Plan for the Circular Economy. COM (2015) 614. European Commission, Brussels, Belgium.

EC, 2015b. Proposal for a Directive of the European Parliament and of the Council Amending Directive 94/62/EC on Packaging and Packaging Waste. COM(2015) 596. European Commission, Brussels, Belgium.

Eriksen, M., Lebreton, L.C., Carson, H.S., Thiel, M., Moore, C.J., Borerro, J.C., et al., 2014. Plastic pollution in the world's oceans: more than 5 trillion plastic pieces weighing over 250,000 tons afloat at sea. PLoS One 9 (12), e111913.

Eriksson, O., Finnveden, G., 2017. Energy recovery from waste incineration-the importance of technology data and system boundaries on $\mathrm{CO}_{2}$ emissions. Energies 10 (4), 539.

Gabbatiss, J., 2018. Plastic-eating Enzyme Accidentally Created by Scientists Could Help Solve Pollution Crisis. https://www.independent.co.uk/news/science/plastic-eatingenzyme-pollution-solution-waste-bottles-bacteria-portsmouth-a8307371.html.

Geissdoerfer, M., Savaget, P., Bocken, N.M., Hultink, E.J., 2017. The circular economy-a new sustainability paradigm? Journal of Cleaner Production 143, 757-768.

Goldstein, M., 2012. Pacific Plastic, Sea Skaters, and the Media: Behind the Scenes of My Recent Paper. http://www.deepseanews.com/2012/05/pacific-plastic-sea-skaters-and-themedia-behind-the-scenes-of-my-recent-paper/.

Gradus, R.H., Nillesen, P.H., Dijkgraaf, E., van Koppen, R.J., 2017. A cost-effectiveness analysis for incineration or recycling of Dutch household plastic waste. Ecological Economics $135,22-28$.

Grant, R., 2016. Why Scientists Are Losing the Fight to Communicate Science to the Public. https://www.theguardian.com/science/occams-corner/2016/aug/23/scientists-losingscience-communication-skeptic-cox.

Green, D.S., Boots, B., O'Connor, N.E., Thompson, R., 2016. Microplastics affect the ecological functioning of an important biogenic habitat. Environmental Science \& Technology 51 (1), 68-77.

Guglielmi, G., 2017. In the next 30 years, we'll make four times more plastic waste than we ever have. Science. http://www.sciencemag.org/news/2017/07/next-30-years-we-11-make-fourtimes-more-plastic-waste-we-ever-have. 
Haward, M., 2018. Plastic pollution of the world's seas and oceans as a contemporary challenge in ocean governance. Nature Communications 9 (1), 667.

Hossain, M.U., Poon, C.S., Dong, Y.H., Xuan, D., 2018. Evaluation of environmental impact distribution methods for supplementary cementitious materials. Renewable and Sustainable Energy Reviews 82, 597-608.

Huysman, S., De Schaepmeester, J., Ragaert, K., Dewulf, J., De Meester, S., 2017. Performance indicators for a circular economy: a case study on post-industrial plastic waste. Resources, Conservation and Recycling 120, 46-54.

IP, 2017. Towards a Circular Economy-Waste Management in the EU. IP/G/STOA/FWC/2013001/LOT 3/C3. http://www.europarl.europa.eu/RegData/etudes/STUD/2017/581913/EPRS_ STU(2017)581913_EN.pdf.

Jambeck, J.R., Geyer, R., Wilcox, C., Siegler, T.R., Perryman, M., Andrady, A., et al., 2015. Plastic waste inputs from land into the ocean. Science 347 (6223), 768-771.

Korhonen, J., Honkasalo, A., Seppälä, J., 2018. Circular economy: the concept and its limitations. Ecological Economics 143, 37-46.

Lamb, J.B., Willis, B.L., Fiorenza, E.A., Couch, C.S., Howard, R., Rader, D.N., et al., 2018. Plastic waste associated with disease on coral reefs. Science 359 (6374), 460-462.

MacArthur, E., 2017. Beyond plastic waste. Science. http://science.sciencemag.org/content/358/ $6365 / 843$.

PiP, 2017. Person in the Port Project. United Nations University, Bonn. http://collections.unu. edu/eserv/UNU:6349/PiP_Report.pdf.

Plastics, 2017. Plastics - the Facts. PlasticsEurope. Brussels- Association of Plastics Manufacturers, Brussels. https://www.plasticseurope.org/download_file/force/1055/181.

Politico, 2018. Hope for Circular Economy Jobs Could Be a Waste. https://www.politico.eu/ article/circular-economy-jobs-waste-garbage-trash-recycling/.

Rochman, C.M., 2018. Microplastics research-from sink to source. Science 360 (6384), $28-29$.

Soapbox Science, 2012. Reaching Out: Science Has a PR Problem. http://blogs.nature.com/ soapboxscience/2012/05/30/reaching-out-science-has-a-pr-problem.

Stephan Schmidheiny with BCSD, 1992. Changing Course: A Global Perspective on Development and the Environment. MIT Press, Cambridge, MA.

Sussarellu, R., Suquet, M., Thomas, Y., Lambert, C., Fabioux, C., Pernet, M.E.J., et al., 2016. Oyster reproduction is affected by exposure to polystyrene microplastics. Proceedings of the National Academy of Sciences 113 (9), 2430-2435.

ten Brink, P., et al., 2018. Circular Economy Measures to Keep Plastics and Their Value in the Economy, Avoid Waste and Reduce Marine Litter. Economics Discussion Papers, No. 2018-3. Kiel Institute for the World Economy (IfW), Kiel.

Van Eygen, E., Laner, D., Fellner, J., 2018. Circular economy of plastic packaging: current practice and perspectives in Austria. Waste Management 72, 55-64.

Wei, R., Zimmermann, W., 2017. Biocatalysis as a green route for recycling the recalcitrant plastic polyethylene terephthalate. Microbial Biotechnology 10, 1302-1307.

Wilcox, C., Van Sebille, E., Hardesty, B.D., 2015. Threat of plastic pollution to seabirds is global, pervasive, and increasing. Proceedings of the National Academy of Sciences 112 (38), 11899-11904.

Winans, K., Kendall, A., Deng, H., 2017. The history and current applications of the circular economy concept. Renewable and Sustainable Energy Reviews 68, 825-833. 